\title{
Use of antidepressants in the treatment of major depressive disorder in primary care during a period of economic crisis
}

\author{
Antoni Sicras-Mainar' \\ Ruth Navarro-Artieda ${ }^{2}$ \\ 'Research Unit, Badalona Serveis \\ Assistencials SA, ${ }^{2}$ Medical \\ Documentation Unit, Hospital \\ Germans Trias i Pujol, Badalona, \\ Barcelona, Spain
}

This article was published in the following Dove Press journal:

Neuropsychiatric Disease and Treatment

30 December 2015

Number of times this article has been viewed

Objective: To describe antidepressant (AD) use in the treatment of major depressive disorder during a period of economic crisis.

Patients and methods: This was a retrospective, observational study using population-based databases. Two periods were considered: 1) 2008-2009, precrisis, and 2) 2012-2013, economic crisis. Certain inclusion/exclusion criteria were taken into account for the study (initiation of AD treatment). Patients were followed up for 12 months. The main measures were use (defined daily doses), epidemiologic measures, strategies used and treatment persistence, referrals, and use of resources. Statistical significance was set at $P<0.05$.

Results: In the precrisis period, 3,662 patients were enrolled, and 5,722 were enrolled in the period of economic crisis. Average age was 58.8 years and $65.4 \%$ were women. Comparing the two periods, major depressive disorder prevalence was $5.4 \%$ vs $8.1 \%, P<0.001$. During the period of economic crisis, AD use rose by $35.2 \%$ and drug expenditures decreased by $38.7 \%$. Defined daily dose per patient per day was $10.0 \mathrm{mg}$ vs $13.5 \mathrm{mg}$, respectively, $P<0.001$. At 12-month follow-up, the majority of patients $(60.8 \%)$ discontinued the treatment or continued on the same medication as before, and in $23.3 \%$ a change of $\mathrm{AD}$ was made.

Conclusion: Primary health care professionals are highly involved in the management of the illness; in addition, during the period of economic crisis, patients with major depressive disorder showed higher rates of prevalence of the illness, with increased use of AD drugs.

Keywords: consumption, antidepressants, economic crisis

\section{Introduction}

Since about 2007, the socioeconomic situation in most European countries has worsened, resulting in higher levels of national debt and a decline in gross domestic product. $^{1,2}$ The majority of European countries have been affected by the economic crisis, but Spain is one of the countries that has suffered the worst consequences, among which are high rates of unemployment and a deterioration in finances, with anticrisis policies based on a reduction of spending on social welfare. ${ }^{3,4}$

The economic crisis has negative effects on the physical and mental health of the population. ${ }^{4}$ Also, unemployment and other associated factors (impoverishment, social isolation, or unhealthy behaviors) are related to a higher prevalence of mental disorders in general and to depressive disorder in particular. ${ }^{5,6}$ Depression is a major public health problem because of its high prevalence and impact on the use of health resources and on the individual's productivity. ${ }^{7}$ According to some studies, the estimated overall annual prevalence of major depressive disorder (MDD) in Spain is $3.9 \%$ and lifetime prevalence is estimated at $10.5 \%$. A total of $14 \%$ of patients seen

Correspondence: Antoni Sicras-Mainar Research Unit, Calle Gaietà Soler, 6-8 entlo, 089। I Badalona, Barcelona, Spain Tel +34935072684

Email asicras@bsa.cat 
in primary care (PC) in Spain have MDD. ${ }^{8}$ Some studies have shown a significant increase in this disorder since the financial crisis began. Lee et $\mathrm{al}^{9}$ (Asia) described an increase in MDD between 2007 and 2009, from $8.5 \%$ to $12.5 \%$, and observed that pattern and severity the symptom's of depression were similar in both periods. Economou et al ${ }^{10}$ (Greece) showed that the impact of the economic crisis on the mental health of the population is widespread and that health services should consider prevention of MDD as well as its diagnosis and appropriate treatment as a priority. In our country (Spain), Gili et $\mathrm{al}^{11}$ concluded that the economic recession has increased the prevalence of mental disorders and alcohol abuse among patients in PC, especially in families suffering from unemployment and unable to make their mortgage payments. Iglesias García et $\mathrm{al}^{12}$ in a particular region, Asturias, showed that the variation in socioeconomic indicators during the economic crisis is not associated with any increase in the demand for care for mental disorders but that, nevertheless, there is a negative correlation between the unemployment rate and the demand for care.

Antidepressants (ADs) are the mainstay of pharmacological treatment for MDD in order to achieve sustained remission of the symptoms. ${ }^{13}$ As a result, in parallel with the increase in the prevalence of MDD, a rise in AD drug consumption has been observed during the period of economic crisis, although it is unknown whether there have been any changes in the prescription's pattern. ${ }^{14,15}$ The available evidence regarding prescribing patterns of these patients in routine clinical practice settings is scarce, so the conduct of this study may be of interest.

The aim of the study was to describe the prescribing patterns and long-term use of ADs as treatment for MDD, during a period of economic restriction, in the $\mathrm{PC}$ health setting and in a context of routine clinical practice. In addition, the referral to specialists' rate and persistence to treatment was assessed.

\section{Patients and methods Design and study population}

A retrospective, longitudinal, multicenter, observational study was conducted, based on a review of the medical records (computerized databases with dissociated data) of patients followed up in an outpatient setting. The study population consists of patients treated at the seven PC centers and at the Hospital Municipal of Badalona (on an outpatient basis), under the management of Badalona Serveis Assistencials, a service provider under contract with the Catalan Health Service. The population served by these centers is predominantly urban and mainly industrial working class of lower-middle socioeconomic status.

\section{Inclusion and exclusion criteria}

All patients in the study population who were diagnosed with MDD according to International Classification of Primary Care-2 (ICPC-2) ${ }^{16}$ code P76, either as a first recurrent episode or prevalent and who started on a new AD treatment regimen during 2008-2009 (precrisis period) or 2012-2013 (period of economic crisis) were included in the study. These patients (in the two study periods) had to meet the following characteristics: 1) age $\geq 18$ years; 2) be treated with an AD in the N06A subgroup (as per Anatomical Therapeutic Chemical codes); ${ }^{17} 3$ ) must not have received any $\mathrm{AD}$ treatment within 12 months prior to the diagnosis (to be sure that it was a new episode in prevalent cases); 4) the prescription had to fulfill criteria for minimum adequate treatment length (at least 60 days of treatment after the first AD prescription); 5) had to be active patients in the database for a minimum of 12 months before a new AD treatment; 6) had to be enrolled in the long-term medication prescription program with a record of daily doses, time interval, and duration of each treatment being administered; two or more prescriptions during the follow-up period; and 7) a regular follow-up of these patients during the course of the study period had to be ensured (two or more health data entries in the computer system). Excluded from the study were 1) patients transferred to other centers or those who were registered elsewhere and 2) patients who were permanently institutionalized.

\section{Study populations and follow-up periods}

There were two study groups: 1) patients who started AD treatment during the 2008-2009 period (precrisis) and 2) those who started AD treatment during the 2012-2013 period (period of economic crisis). Patients were followed up for 12 months from the date the AD drug was initially prescribed. The patients were included in separate groups.

\section{Diagnosis of MDD}

The records of patients who were diagnosed with MDD according to ICPC-2 (code P76) were obtained. ${ }^{16}$ Only MDD of P76 code was included.

\section{Sociodemographic and comorbidity variables}

The sociodemographic variables studied were age (continuous and ranges), occupational status (active worker/pensioner), 
sex, and years since onset of the disease (only recurrent cases).

The comorbidity variables as well as personal history based on ICPC- $2^{16}$ classification were hypertension (K86, K87); diabetes mellitus (T89, T90); dyslipidemia (T93); obesity (T82); active tobacco abuse (P17); alcohol abuse (P15, P16); any type of organ failure (heart, liver, and kidney); ischemic heart disease (K74, K75, K76); cerebrovascular accident (K90, K91, K93); dementia or memory disturbances (P70, P20); neurological diseases: Parkinson's disease (N87), epilepsy (N88), multiple sclerosis (N86), and other neurological diseases (N99); and malignant neoplasms (all types: A79, B72-75, D74-78, F75, H75, K72, L71, L97, N74-76, T71-73, U75-79, W72-73, X75-81, Y77-79). The following comorbidity summary measures were used for each patient treated: 1) the Charlson Comorbidity Index ${ }^{18}$ as an indicator of the severity of the patient's condition and 2) an index of comorbidity (the Adjusted Clinical Groups System), which classifies patients according to isoresource consumption group. ${ }^{19}$ The software includes the resource utilization bands that are used to rank patients on the basis of their overall morbidity and group the individuals into one of five mutually exclusive categories (1: healthy or very low morbidity, 2: low morbidity, 3: moderate morbidity, 4: high morbidity, and 5: very high morbidity).

\section{Medications given, persistence with treatment, and resource use}

Active ingredients (molecule) from the N06A subgroup $\mathrm{AD}$ drugs indicated for the treatment of MDD according to the Anatomical Therapeutic Chemical classification system ${ }^{17}$ were obtained, as well as those of the concomitant medications including sedatives/hypnotics (N05C) and antipsychotics (N05A). The information was obtained from the medication dispensing records on file in the CatSalut (Catalan Health Service) electronic prescription system through the Registro Central de Medicamentos y Productos Sanitarios. The choice of drug for each individual patient was determined by the attending physician according to routine clinical practice. AD use was obtained through the defined daily dose (DDD) and also from expenditures (retail price of each package prescribed). ${ }^{17}$

The following options were considered as possible strategies for treatment discontinuation (completion) and/or change in $\mathrm{AD}$ treatment by the $\mathrm{PC}$ or specialist physician: 1) change in $\mathrm{AD}$ treatment (selection of a new drug); 2) adding another $\mathrm{AD}$ (combination) or adding a new drug without any intrinsic $\mathrm{AD}$ properties (an AD booster, such as lithium and atypical antipsychotics), and 3) an increase in the dose of the initial AD.

Persistence with treatment was defined as the length of time, measured in months (discontinuation or switch) at least 60 days after the initial prescription. In order to assess direct resource use, the number of and reasons for referral to a psychiatrist specialist and/or mental health referral center were obtained. It was found that the main reasons were 1) the severity of the episode, 2) lack of response to treatment, and 3) other reasons. The number of visits in PC and specialized care (psychiatry) were also recorded. The number of days of temporary disability were recorded as indirect resource use.

\section{Confidentiality of information}

The confidentiality of the records (which are anonymous and unlinked) has been respected in this study, in accordance with Organic Law 15/1999, of December 13, concerning the protection of personal data. The study was classified by the Spanish Agency for Medicines and Health Products (SAMHP) and received approval from the Clinical Research Ethics Committee of the Hospital Universitari Germans Trias i Pujol in Badalona.

\section{Statistical analysis}

To ensure the quality of the records, data validation was performed. Univariate descriptive statistical analysis was performed by which mean values, typical/standard deviation, 95\% confidence intervals, and interquartile range (median and 25-75 percentiles) were calculated. Normality of the distribution was tested using the Kolmogorov-Smirnov test. Analysis of variance, chi-squared test, and Pearson's linear correlation test were used. SPSS/Win version 17.0 was used, and threshold for statistical significance was set at $P<0.05$.

\section{Results \\ General characteristics}

Out of an initial population of 89,353 people aged $\geq 18$ years, a total of 74,163 were seen during the preeconomic crisis period (2008-2009). A total of 4,005 of these patients had a diagnosis of MDD, and in the final analysis, there were a total of 3,662 patients who met the inclusion/exclusion criteria and were able to be followed for the duration of the study period (Figure 1). During the period of economic crisis (2012-2013), out of an initial population of 90,831 people aged $\geq 18$ years, 74,758 were seen. A total of 6,055 patients were diagnosed with MDD and, at the end, a total of 5,722 were analyzed (Figure 1). 


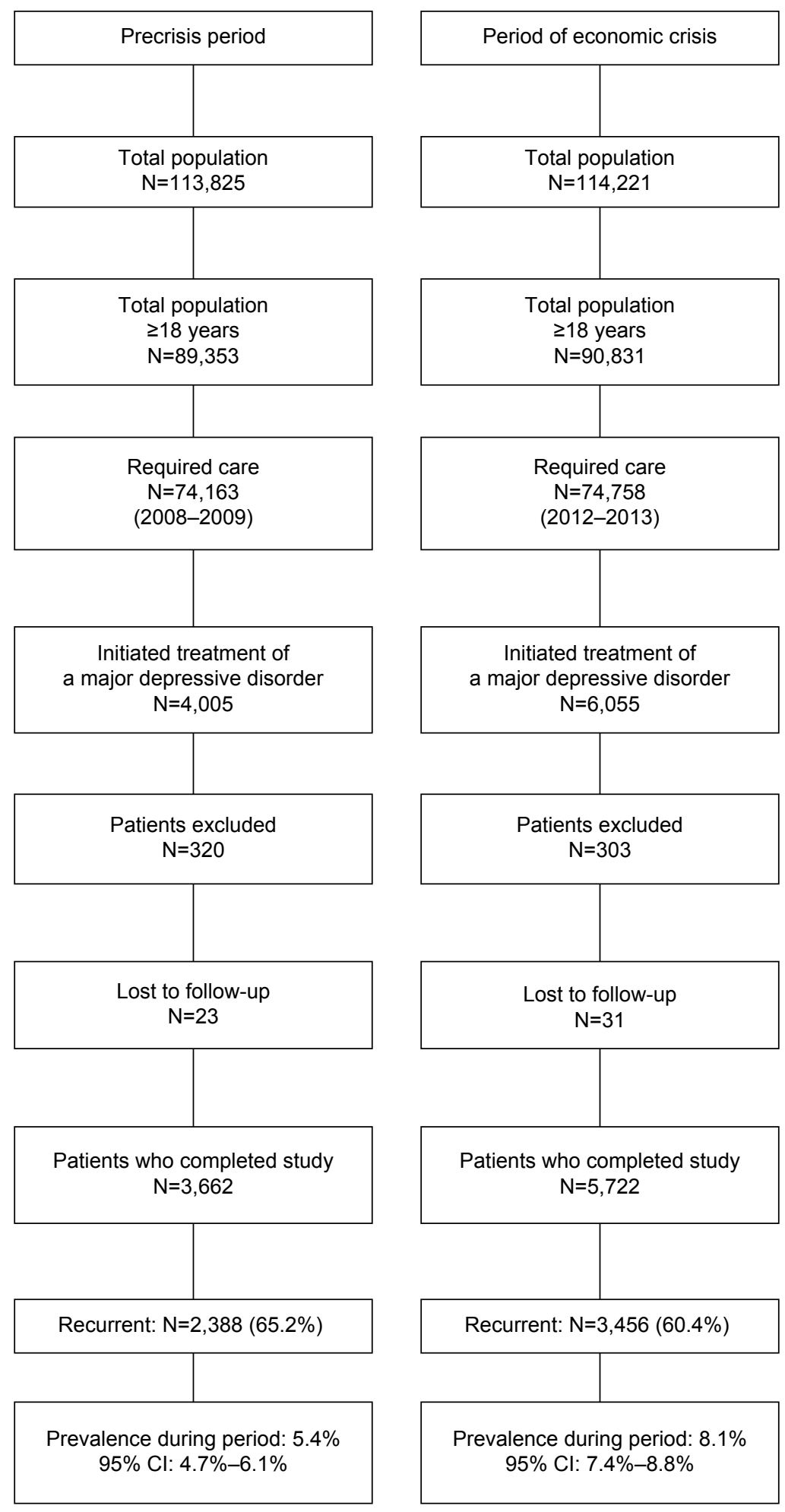

Figure I General outline of the study. Abbreviation: $\mathrm{Cl}$, confidence interval.

A comparison of the two periods showed that the prevalence of diagnosed MDD was 5.4\% (95\% confidence interval: $4.7 \%-6.1 \%$ ) in the precrisis period, as opposed to $8.1 \%$ (95\%: $7.4 \%-8.8 \%), P<0.001$ in the period of economic crisis.
Table 1 shows the baseline characteristics of the patients with a new episode of MDD in each study period. Mean age was 58.8 years, $65.4 \%$ were women, and resource utilization band score was 2.7 points. Generally speaking, dyslipidemia (53.9\%), hypertension (41.2\%), and obesity (22.3\%) were the 
Table I Baseline characteristics of the patients in each study period

\begin{tabular}{|c|c|c|c|c|}
\hline Study groups & Precrisis period & Period of economic crisis & Total & $P$-value \\
\hline \multicolumn{5}{|l|}{ Number of patients } \\
\hline$N(\%)$ & $3,662(39.0)$ & $5,722(61.0)$ & $9,384(100)$ & \\
\hline \multicolumn{5}{|c|}{ Sociodemographic characteristics } \\
\hline Mean age, years & $58.0(15.7)$ & $59.3(15.6)$ & $58.8(15.6)$ & $<0.001$ \\
\hline I8-44 years & $20.5 \%$ & $19.6 \%$ & $19.9 \%$ & \\
\hline $45-64$ years & $45.0 \%$ & $45.2 \%$ & $45.2 \%$ & \\
\hline $65-74$ years & $17.0 \%$ & $18.8 \%$ & $18.1 \%$ & \\
\hline$>74$ years & $17.5 \%$ & $16.4 \%$ & $16.8 \%$ & 0.091 \\
\hline Sex (women) & $64.7 \%$ & $65.8 \%$ & $65.4 \%$ & 0.257 \\
\hline Occupational status, retired & $44.6 \%$ & $46.0 \%$ & $45.5 \%$ & 0.200 \\
\hline \multicolumn{5}{|l|}{ Overall morbidity } \\
\hline Mean Charlson's index & $0.5(0.7)$ & $0.5(0.7)$ & $0.5(0.7)$ & 0.804 \\
\hline Mean RUBs & $2.8(0.7)$ & $2.7(0.7)$ & $2.7(0.7)$ & 0.101 \\
\hline I (very low comorbidity) & $1.4 \%$ & $2.5 \%$ & $2.1 \%$ & \\
\hline 2 (low comorbidity) & $32.0 \%$ & $37.7 \%$ & $35.4 \%$ & \\
\hline 3 (moderate comorbidity) & $55.8 \%$ & $50.5 \%$ & $52.6 \%$ & \\
\hline 4 (high comorbidity) & $9.2 \%$ & $8.2 \%$ & $8.6 \%$ & \\
\hline 5 (very high comorbidity) & $1.6 \%$ & $1.1 \%$ & $1.3 \%$ & 0.071 \\
\hline \multicolumn{5}{|l|}{ Associated comorbidities } \\
\hline Hypertension & $40.0 \%$ & $42.0 \%$ & $41.2 \%$ & 0.053 \\
\hline Diabetes mellitus & $17.8 \%$ & $18.3 \%$ & $18.1 \%$ & 0.560 \\
\hline Dyslipidemia & $53.1 \%$ & $54.4 \%$ & $53.9 \%$ & 0.193 \\
\hline Obesity & $21.8 \%$ & $22.7 \%$ & $22.3 \%$ & 0.314 \\
\hline Active smokers & $23.6 \%$ & $22.1 \%$ & $22.7 \%$ & 0.090 \\
\hline Alcohol abuse & $3.8 \%$ & $3.1 \%$ & $3.4 \%$ & 0.082 \\
\hline Ischemic heart disease & $6.5 \%$ & $5.8 \%$ & $6.1 \%$ & 0.187 \\
\hline Cerebrovascular accident & $11.3 \%$ & $11.3 \%$ & $11.3 \%$ & 0.917 \\
\hline Cardiovascular events & $15.7 \%$ & $15.4 \%$ & $15.5 \%$ & 0.681 \\
\hline Organ failure & $15.9 \%$ & $16.2 \%$ & $16.1 \%$ & $0.77 I$ \\
\hline Asthma & $8.1 \%$ & $7.3 \%$ & $7.6 \%$ & 0.205 \\
\hline COPD & $7.8 \%$ & $8.8 \%$ & $8.4 \%$ & 0.109 \\
\hline Neurological diseases & $2.1 \%$ & $2.1 \%$ & $2.1 \%$ & 0.896 \\
\hline Dementia (all types) & $5.5 \%$ & $5.2 \%$ & $5.3 \%$ & 0.450 \\
\hline Malignant neoplasms & $11.9 \%$ & $10.6 \%$ & $11.1 \%$ & $0.07 \mid$ \\
\hline \multicolumn{5}{|l|}{ Characteristics of the illness } \\
\hline Evolution of the illness, years & $4.8(4.0)$ & $5.5(5.0)$ & $5.2(4.7)$ & $<0.001$ \\
\hline Prevalent cases $(\mathrm{N}=5,844)$ & $65.2 \%$ & $60.4 \%$ & $62.3 \%$ & $<0.001$ \\
\hline
\end{tabular}

Notes: Values are expressed as percentage or mean (standard deviation). P indicates statistical significance.

Abbreviations: RUBs, resource utilization bands; COPD, chronic obstructive pulmonary disease.

most frequent comorbidities. Of the 9,384 episodes of MDD (start of treatment), 3,662 (39.0\%) occurred in the precrisis period and 5,722 (61.0\%) in the period of economic crisis. Overall, the two groups were comparable.

\section{$A D$ drug use}

Table 2 provides the total AD drug use and expenditure during the two study periods. During the period of economic crisis, the total consumption of ADs (measured in DDD) rose by $35.2 \%$ (precrisis: $26,728,274 \mathrm{mg}$; period of economic crisis $56,446,109 \mathrm{mg}$ ). This increase in total AD consumption was mainly due to the other ADs (44.2\%) and selective serotonin reuptake inhibitors (SSRIs, 37.4\%) class groups, whereas there was a decline in the use of tricyclic ADs $(-42.2 \%)$. Overall, the rate of consumption per patient was higher (DDD/patient/day; $10.0 \mathrm{mg}$ vs $13.5 \mathrm{mg}, P<0.001)$. Per active ingredient, increases in the percentage of use of sertraline $(12.1 \%$ vs $15.3 \%, P<0.001)$, escitalopram (12.7\% vs $13.2 \%, P=0.001)$, and duloxetine (7.8\% vs $9.7 \%$, $P<0.001)$ were noted. These differences between the two periods were statistically significant.

During the period of economic crisis, pharmaceutical spending on ADs per patient decreased in comparison to the precrisis period ( $€ 392$ as opposed to $€ 241$, difference: $-38.7 \%$, $P<0.001)$. Percentagewise, by active ingredient, the highest expenditure was on duloxetine $(17.8 \%$ in the precrisis period compared to $29.8 \%$ in the period of economic crisis, $P<0.001)$.

Drug consumption, in general, as well as use of ADs as first line of treatment (initial prescription) per patient during 


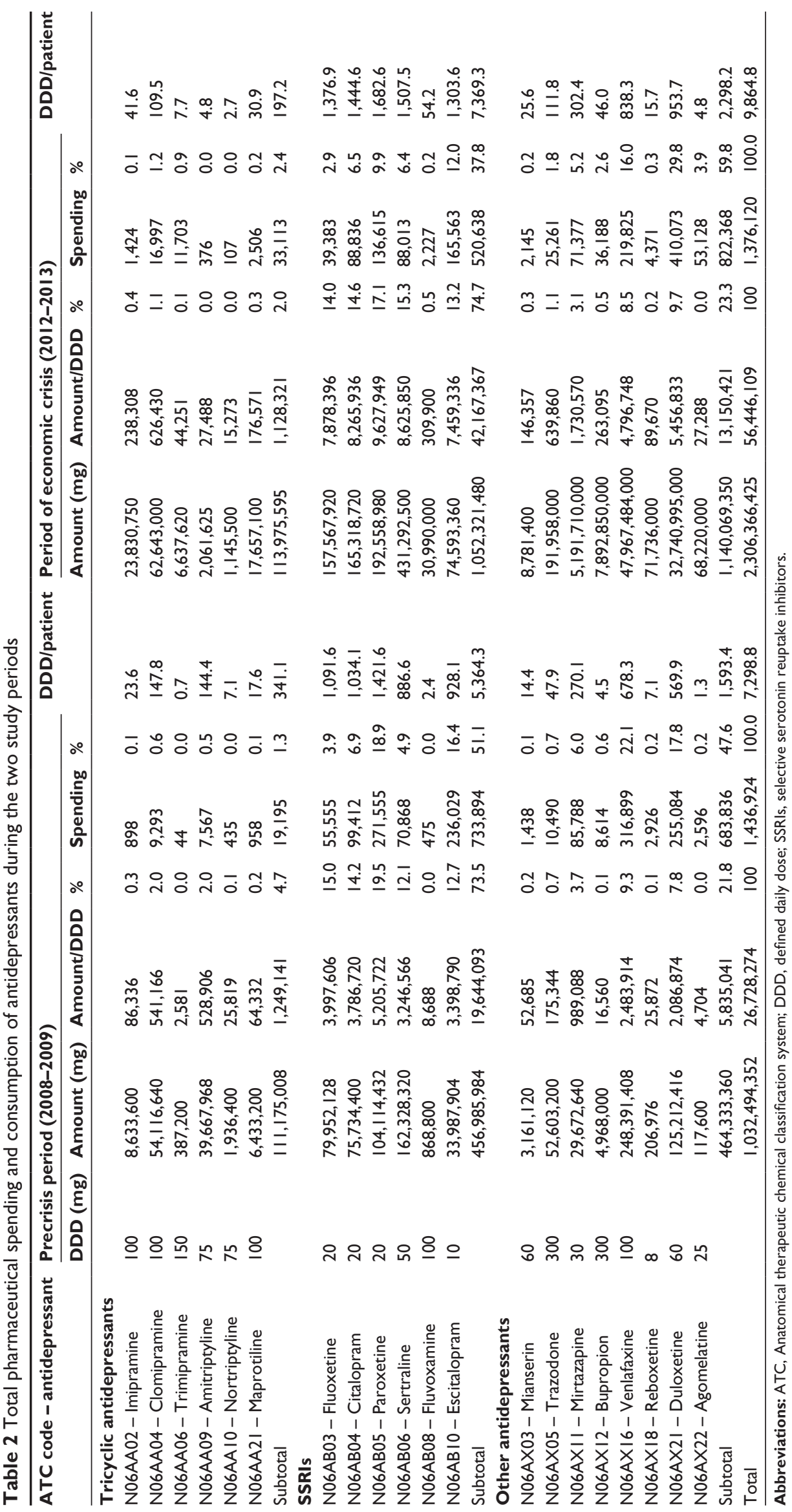


the two periods studied is described in Table 3. Average consumption of prescribed ADs per patient during the two periods was similar, so was the use of antipsychotics (quetiapine) and lithium. However, there was a slight decline in average use of sedatives/hypnotics per patient (68.8\% vs $66.2 \% ; P=0.008)$. Lorazepam (15.4\%), alprazolam (11.9\%), and lormetazepam $(10.4 \%)$ were the most commonly prescribed drugs. With regard to the use of ADs as first line of treatment per therapeutic class, a slight increase in the frequency of use of other ADs $(22.7 \%$ vs $23.8 \% ; P<0.001)$ is to be noted, especially for prevalent patients.

\section{Persistence to treatment}

Table 4 shows the initial persistence to treatment with ADs, treatment strategies, referrals, and resource use during the two periods studied. At 6 months, persistence to treatment was $49.7 \%$ in contrast with $51.8 \%$, in the precrisis and crisis periods, respectively $(P=0.002)$. On the other hand, the strategies followed during the year of follow-up were similar for the two periods: $61.7 \%$ of patients discontinued their medications in the first period compared to $60.4 \%$ in the second. Of the patients whose initial treatment regimen was modified, $1,401(38.3 \%)$ in the precrisis period and
$2,316(40.1 \%)$ in the period of economic crisis, the majority, $60.8 \%$, switched to another medication, while dosage was increased in $23.3 \%$ of cases and in $15.9 \%$ the medication was boosted.

\section{Resources use and therapeutic strategies}

During the period of economic crisis, there was a higher proportion of referrals to a specialist $(20.3 \%$ vs $23.8 \%$; $P<0.001)$. The average number of visits to $\mathrm{PC}$ also rose $(8.2 \%$ vs $9.9 \% ; P<0.001)$, although there were no significant changes in the average number of visits to specialist care. A lower average number of days of temporary disability was observed (13.6 as opposed to $8.9 ; P<0.001$ ).

The therapeutic strategies used for AD treatment are described in Table 5. At 12-month follow-up, the majority of patients (60.8\%) had discontinued their initial medication; in $23.3 \%$, a change in $\mathrm{AD}$ prescription was made, $9.1 \%$ were given an additional AD, and in $6.5 \%$, the AD dose was increased. There were no statistically significant (relevant) differences between the two periods analyzed (precrisis and period of economic crisis).

Generally speaking, patients for whom no changes were made in $\mathrm{AD}$ medications were new cases (precrisis: 40.6\%;

Table 3 Consumption of medicines and use of antidepressants in first line of treatment (initial prescription) during the two study periods

\begin{tabular}{|c|c|c|c|}
\hline Groups & Precrisis period & Period of economic crisis & $P$-value \\
\hline \multicolumn{4}{|l|}{ Number of patients } \\
\hline$N(\%)$ & $3,662(39.0)$ & $5,722(61.0)$ & \\
\hline \multicolumn{4}{|l|}{ Consumption of medicines ${ }^{a}$} \\
\hline Average number of antidepressants & I.4 (0.7) & $\mathrm{I} .4(0.7)$ & 0.559 \\
\hline One & $68.8 \%$ & $69.7 \%$ & \\
\hline Two & $24.2 \%$ & $22.1 \%$ & \\
\hline Three or more & $7.0 \%$ & $8.1 \%$ & $0.07 I$ \\
\hline Antipsychotics & $10.7 \%$ & $9.5 \%$ & 0.074 \\
\hline Hypnotics/sedatives & $68.8 \%$ & $66.2 \%$ & 0.008 \\
\hline Lithium & $2.5 \%$ & $2.6 \%$ & 0.084 \\
\hline \multicolumn{4}{|l|}{ First line of treatment ${ }^{b}$} \\
\hline Tricyclic antidepressants & $8.0 \%$ & $6.9 \%$ & 0.089 \\
\hline N06AA04 - Clomipramine & $1.8 \%$ & $1.7 \%$ & \\
\hline N06AA09 - Amitriptyline & $5.3 \%$ & $4.4 \%$ & \\
\hline SSRIs & $69.3 \%$ & $69.3 \%$ & 0.382 \\
\hline N06AB03 - Fluoxetine & $14.0 \%$ & $12.4 \%$ & \\
\hline N06AB04 - Citalopram & $15.2 \%$ & $17.3 \%$ & \\
\hline N06AB05 - Paroxetine & $22.2 \%$ & $19.8 \%$ & \\
\hline N06AB06 - Sertraline & $8.5 \%$ & $9.3 \%$ & \\
\hline N06ABI0 - Escitalopram & $9.4 \%$ & $10.3 \%$ & \\
\hline Other antidepressants & $22.7 \%$ & $23.8 \%$ & $<0.001$ \\
\hline N06AX05 - Trazodone & $1.7 \%$ & $2.5 \%$ & \\
\hline N06AXII - Mirtazapine & $3.9 \%$ & $3.9 \%$ & \\
\hline N06AXI6 - Venlafaxine & $9.3 \%$ & $9.5 \%$ & \\
\hline N06AX21 - Duloxetine & $7.0 \%$ & $6.0 \%$ & \\
\hline
\end{tabular}

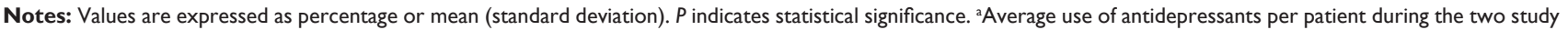
periods. ${ }^{b}$ Most commonly used medications in first line of treatment (initial prescription). 
Table 4 Description of persistence, treatment strategies, referrals to specialist care and use of resources during the two study periods

\begin{tabular}{|c|c|c|c|}
\hline Study groups & Precrisis period & Period of economic crisis & $P$-value \\
\hline \multicolumn{4}{|l|}{ Number of patients } \\
\hline$N(\%)$ & $3,662(39.0)$ & $5,722(61.0)$ & \\
\hline \multicolumn{4}{|l|}{ Duration of treatment, months } \\
\hline Mean (SD) & $8.9(3.7)$ & $8.8(3.8)$ & 0.552 \\
\hline Median (P25-P75) & $11.0(5.0-12.0)$ & $11.0(5.0-12.0)$ & \\
\hline \multicolumn{4}{|l|}{ Persistence with treatment } \\
\hline Average, 6 months & $74.3 \%$ & $73.5 \%$ & 0.371 \\
\hline $95 \% \mathrm{Cl}$ & $72.9 \%-75.7 \%$ & $72.4 \%-74.6 \%$ & \\
\hline Average, 12 months & $49.7 \%$ & $51.8 \%$ & 0.002 \\
\hline $95 \% \mathrm{Cl}$ & $48.1 \%-51.3 \%$ & $50.5 \%-53.1 \%$ & \\
\hline \multicolumn{4}{|l|}{ Treatment strategy } \\
\hline Discontinuation/no changes in medication & $61.7 \%$ & $60.4 \%$ & \\
\hline Change in the initial regimen & $38.3 \%$ & $39.6 \%$ & 0.444 \\
\hline Dosage increased & $8.8 \%$ & $9.4 \%$ & \\
\hline Switch to another medication & $23.0 \%$ & $23.5 \%$ & \\
\hline Medication boosted & $6.4 \%$ & $6.6 \%$ & 0.597 \\
\hline \multicolumn{4}{|l|}{ Referrals to a specialist } \\
\hline Rate of referrals & $20.3 \%$ & $23.8 \%$ & $<0.001$ \\
\hline $95 \% \mathrm{Cl}$ & $19.0 \%-21.6 \%$ & $22.7 \%-24.9 \%$ & \\
\hline \multicolumn{4}{|l|}{ Reasons for referral } \\
\hline Lack of response to treatment & $9.3 \%$ & $11.0 \%$ & \\
\hline Severity of the illness & $7.9 \%$ & $9.2 \%$ & \\
\hline Other reasons/not specified & $3.1 \%$ & $3.6 \%$ & 0.002 \\
\hline \multicolumn{4}{|l|}{ Use of resources } \\
\hline Average number of primary care visits & $8.2(7.2)$ & $9.9(7.4)$ & $<0.001$ \\
\hline Average number of visits to a specialist & $2.5(1.8)$ & $2.2(1.7)$ & 0.225 \\
\hline Average number of days of temporary disability & $13.6(60.9)$ & $8.9(48.5)$ & $<0.001$ \\
\hline
\end{tabular}

Notes: Values are expressed as percentage or mean (mean [SD]). $P$ indicates statistical significance. Persistence with treatment was defined as the length of time, measured in months (discontinuation or switch), at least 60 days after the initial prescription.

Abbreviations: $\mathrm{Cl}$, confidence interval; SD, standard deviation; $\mathrm{P} 25-\mathrm{P} 75$, 25th to 75th percentiles.

period of economic crisis: $43.3 \%$ ), showed high persistence with treatment (precrisis: $58.2 \%$; period of economic crisis: 61.2\%), were treated with SSRIs (precrisis: $74.9 \%$; period of economic crisis: $76.3 \%$ ), and had a low rate of referral to a specialist (precrisis: $1.9 \%$; period of economic crisis: 5.8\%). Patients who had their AD doses increased showed low persistence with treatment (precrisis: $24.8 \%$; period of economic crisis: $19.7 \%$ ). The patients whose AD treatment regimen was changed were given a higher than average amount of $\mathrm{AD}$ (precrisis: 2.3; period of economic crisis: 2.3), had a higher rate of referral to a specialist (precrisis: $58.1 \%$; period of economic crisis: $61.4 \%$ ), more visits to a specialist (precrisis: 7.3; period of economic crisis: 6.6), and a higher number of days of temporary disability (precrisis: 18.5; period of economic crisis: 12.2).

Patients who were given a new AD or adjuvant treatment were for the most part prevalent cases (precrisis: $71.6 \%$; period of economic crisis: $75.0 \%$ ), with a higher percentage of referral to a specialist (precrisis: $58.1 \%$; period of economic crisis: $51.8 \%$ ), more visits to a specialist (precrisis: 6.3; period of economic crisis: 6.5 ), and higher percentage use of other ADs (precrisis: $35.6 \%$; period of economic crisis: $34.5 \%$ ) and antipsychotics (precrisis: $97.9 \%$; period of economic crisis: $92.9 \%$ ). When comparing the period of economic crisis to the precrisis period, the most relevant changes were seen in patients whose AD treatment was switched or who were given additional treatment (Table 5). The medications most prescribed by specialists as second-line treatment (35.8\% of the total) were 1) other ADs (22.7\%), 2) SSRIs (13.1\%), and 3) tricyclic ADs (3.3\%). Duloxetine (6.5\%), venlafaxine (5.4\%), escitalopram (5.1\%), citalopram (4.4\%), and trazodone (2.7\%) were the most commonly prescribed drugs.

\section{Discussion}

The study reveals that during the period of economic crisis, there were higher prevalence rates of diagnosis of MDD along with a higher use of AD drugs in routine clinical practice settings. It is worth noting that in the absence of a standardized methodology, caution should be exercised when interpreting the results, which should be considered within the context of the health services provider's own setting, thus 


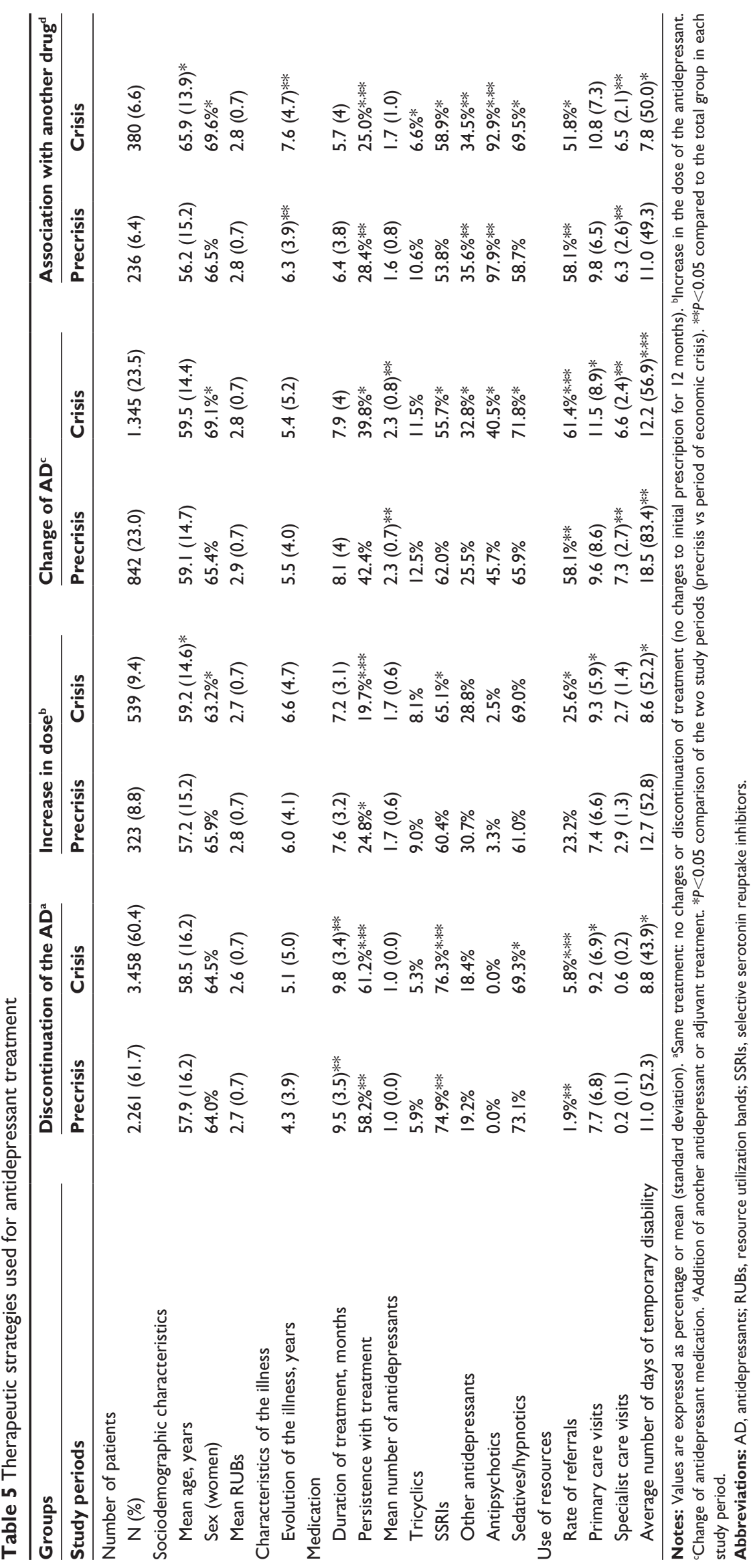


compelling us to be very careful about the external validity of the findings. One of the strengths of the study relies on the large number of patients included in the study population, keeping in mind that few studies on this topic have been reported so far.

In our study, when comparing the two periods, the analysis showed that prevalence rose from $5.4 \%$ to $8.1 \%$ in the period of economic crisis. By way of example, Gili et a ${ }^{20}$ and Bartoll et $\mathrm{al}^{5}$ showed that the presence of an economic recession results in a higher frequency of mental health problems, especially in families suffering from unemployment and who face difficulties in making mortgage payments. Likewise, the study by Agudelo-Suárez et $\mathrm{al}^{21}$ describes how mental health of immigrant workers has worsened in Spain during the economic crisis. In most countries, periods of economic crisis cause public health budgets to be reduced and, in general, mental health issues are considered as a lowpriority area due to the stigma of mental illness, among other reasons. Nevertheless, the results are clear: mental health is adversely affected during periods of economic hardship. The study by Lee et $\mathrm{al}^{9}$ shows that 1 ) the impact of the economic crisis on the mental health of the population is widespread; 2) there is a lack of population-based research on the relationship between economic uncertainty and specific mental disorders; 3) prevalence of MDD between 2007 (8.5\%) and 2009 (12.5\%) increased according to DSM-IV criteria; and 4) the pattern of symptoms and severity of episodes during the two periods were similar. Our results are consistent with those of these authors, although in our study the potential causes for MDD were not ascertained.

During the period of economic crisis, consumption of ADs for treatment of MDD increased by $35.2 \%$ while pharmaceutical spending decreased by $38.7 \%$. This pattern is also consistent with the literature reviewed. In most countries, a trend over time toward a rise in prescription of ADs has been observed, although this may also be explained by the increase in the recurrence of mood disorders, by a higher rate of detection and diagnosis by PC physicians, as well as the approvals to extend therapeutic indications for these medications (adjustment disorders, chronic neuropathic pain, detoxication, etc). ${ }^{78}$ In Spain, according to data published by the SAMHP in 2015, the use of AD drugs tripled between 2000 and 2013. The sharpest rise in spending on ADs was for SSRIs with, for example, escitalopram going from 20.4 daily doses per inhabitant in the year 2000 to 52.9 daily doses per inhabitant in 2013. SSRIs accounted for $70.4 \%$ of the total consumption of ADs in 2013. Similarly, the consumption of venlafaxine and duloxetine has also risen while there has been a decline in the use of tricyclic $\mathrm{ADs} .{ }^{22,23}$ Our results are also consistent with these findings from the SAMHP with regard to the consumption of ADs for MDD.

Regarding the decline in pharma spending of AD drugs, the entry into effect of reference pricing for drugs in Spain may be the main reason for this reduction in pharmaceutical expenditures despite the increase in ADs consumption.

A high consumption of benzodiazepines is to be noted, in contrast with the results of studies in other countries where the use of this type of drugs is lower and where stricter prescribing rules are followed. ${ }^{24,25}$ It might be that in our environment there is some discrepancy in clinical practice when it comes to following international recommendations and that patients are hard to persuade about the need to discontinue using this type of medication.

In our study, at 12-month follow-up, the majority of patients $(60.8 \%)$ had discontinued their initial medication, a change in $\mathrm{AD}$ was made in $23.3 \%$ of cases, and in $6.5 \%$ the $\mathrm{AD}$ dose was increased. There were no significant differences between the two study periods studied. With respect to the attitude of PC physicians, our results highlight two aspects that contrast with the recommendations of Clinical Practice Guidelines: 1) a relevant number of patients continue with the initial treatment and 2) the percentage of patients who are prescribed an increase in the dosage of their AD medication is low. Patients whose AD medication was not changed tended to be those who started treatment (possibly with poor compliance) so they probably achieved some improvement, although not enough, and a more conservative attitude was adopted with them. This can be due to side effects or interactions with other medications, patient preferences, inadequate training of the practitioners in pharmacotherapy, associated medical conditions, or other effects not quantified in this study. Initiating concomitant treatment with lithium or other drugs is not standard clinical practice in PC. When there is no response to an $\mathrm{AD}$ after 6-8 weeks of treatment, the guidelines from the scientific associations recommend switching to another $\mathrm{AD}$, first within the same class and later from a different class. Therefore, it seems that in the PC setting, there is little information based on data from studies about which strategies might be most appropriate for the management of treatment-resistant depression and what steps should be taken for the adoption of alternative therapies, which should always be individualized for each patient. However, the issue is open to debate. Substitution or change strategies are widely used, and some studies suggest that it may make sense to follow this type of strategy. Although Thase ${ }^{26}$ described a response rate of $50 \%$ by switching from serotonergic drugs to tricyclic agents, 
it seems that switching to venlafaxine may provide a higher rate of therapeutic response. ${ }^{27}$ The truth of the matter is that there are no conclusive data as to what is the best available treatment alternative for treatment-resistant depression. ${ }^{28}$

During the period of economic crisis, there were more recurrent cases, patients showed a longer time from diagnosis, greater persistence with treatment, more referrals to a specialist, more visits, and fewer days of temporary disability. It is difficult to compare these results as so many different factors are involved, such as the training of health care professionals, the organizational models, resources available and services offered, the psychiatric comorbidities, and the type of patients. Furthermore, in our case, we have only included patients referred to a specialist or center for psychiatric care; referrals to psychotherapy services or social worker were not quantified. Our results are similar to those of Krahn et $\mathrm{al}^{29}$ who observed that younger patients and those with suicidal tendencies (seriousness of illness) and recurrent MDD (prevalent cases) had consumed two or more AD (with a lack of response to treatment). With regard to rates of referral to specialist care, our results are similar to those described in the INTERDEP study, which was conducted in the Autonomous Community of Madrid (Spain). ${ }^{30}$

In this study, limitations inherent to population databased studies apply, such as underrecording of the illness under investigation or potential variations in the registry of their condition by professionals and patients. Potential limitations of the study have to do with certainty in determining the diagnosis of the illness, possible inaccuracies in the diagnostic codes for MDD, and other comorbidities and also in measuring the remission of symptoms or treatment adherence. It is also possible that most severe cases have not been included in the study as these are usually managed at mental health care centers. Likewise, other biases should be considered such as failure to account for the presence or absence of psychotherapeutic interventions or consultations with other medical professionals providing care outside the national health system (private health) as well as the absence of some variables that could influence the final results, such as the patient's socioeconomic status or exposure to work and changes in drug dosage regimens, etc.

Future approaches with regard to this analysis should be focused on replicating the study in other health care institutions and making more studies of cost-effectiveness and treatment adequacy available. In the field of mental health, it becomes essential to strengthen protective factors from the impact of the crisis, especially for vulnerable subgroups such as children, young people, the elderly, and the unemployed or people with severe financial problems. Countries that have a strong social protection system require minor changes to reduce this impact.

\section{Conclusion}

To conclude, during the period of economic crisis, there were higher prevalence rates of diagnosis of MDD along with a higher use of AD drugs in routine clinical practice settings. In addition, primary health care professionals are highly involved in the management of the illness.

\section{Disclosure}

The authors report no conflict of interest in this work.

\section{References}

1. Karanikolos M, Mladovsky P, Cylus J, et al. Financial crisis, austerity, and health in Europe. Lancet. 2013;381(9874):1323-1331.

2. McDaid D, Quaglio G, Correia de Campos A, et al. Health protection in times of economic crisis: challenges and opportunities for Europe. J Public Health Policy. 2013;34:489-501.

3. De Vogli R. The financial crisis, health and health inequities in Europe: the need for regulations, redistribution and social protection. Int J Equity Health. 2014;13:58.

4. Gili M, García Campayo J, Roca M. Economic crisis and mental health SESPAS report 2014. Gac Sanit. 2014;28(suppl 1):104-108.

5. Bartoll X, Palència L, Malmusi D, Suhrcke M, Borrell C. The evolution of mental health in Spain during the economic crisis. Eur J Public Health. 2014;24:415-418.

6. Uutela A. Economic crisis and mental health. Curr Opin Psychiatry. 2010;23:127-130.

7. Haro JM, Palacín C, Vilagut G, et al. Prevalencia de los trastornos mentales y factores asociados: resultados del estudio ESEMeD-España. [Prevalence of mental disorders and associated factors: results from the ESEMeD-Spain study]. Med Clin (Barc). 2006;126:445-451.

8. Sicras-Mainar A, Blanca-Tamayo M, Gutiérrez-Nicuesa L, et al. Impacto de la morbilidad, uso de recursos y costes en el mantenimiento de la remisión de la depresión mayor en España: estudio longitudinal de ámbito poblacional. [Impact of morbidity, resource use and costs on maintenance of remission of major depression in Spain: a longitudinal study in a population setting]. Gac Sanit. 2010;24:13-19.

9. Lee S, Guo WJ, Tsang A, et al. Evidence for the 2008 economic crisis exacerbating depression in Hong Kong. J Affect Disord. 2010;126: $125-133$.

10. Economou M, Madianos M, Peppou LE, Patelakis A, Stefanis CN. Major depression in the era of economic crisis: a replication of a crosssectional study across Greece. J Affect Disord. 2013;145:308-314.

11. Gili M, Roca M, Basu S, McKee M, Stuckler D. The mental health risks of economic crisis in Spain: evidence from primary care centres, 2006 and 2010. Eur J Public Health. 2013;23:103-108.

12. Iglesias García C, Sáiz Martinez P, García-Portilla González MP, et al. Effects of the economic crisis on demand due to mental disorders in Asturias: data from the Asturias Cumulative Psychiatric Case Register (2000-2010). Actas Esp Psiquiatr. 2014;42:108-115.

13. Anderson IM, Ferrier IN, Baldwin RC, et al. Evidence based guidelines for treating depressive disorders with antidepressants: a revision of the 2000 British Association for Psychopharmacology guidelines. J Psychopharmacol. 2008;22:343-396.

14. Alameda-Palacios J, Ruiz-Ramos M, García-Robredo B. Suicidio, prescripción de antidepresivos y desempleo en Andalucía [Suicide, antidepressant prescription and unemployment in Andalusia (Spain)]. Gac Sanit. 2014;28:309-312. 
15. Abbing-Karahagopian V, Huerta C, Souverein PC, et al. Antidepressant prescribing in five European countries: application of common definitions to assess the prevalence, clinical observations, and methodological implications. Eur J Clin Pharmacol. 2014;70:849-857.

16. Lamberts H, Wood M, Hofmans-Okkes ÍM, editors. The Ínternational Classification of Primary Care in the European Community. With a Multi-Language Layer. Oxford: Oxford University Press; 1993.

17. World Health Organization. The Anatomical Therapeutic Chemical Classification System with Defined Daily Doses (ATC/DDD). Geneva: World Health Organization; 2003.

18. Charlson ME, Pompei P, Ales KL, Mackenzie CR. A new method of classifying prognostic comorbidity in longitudinal studies: development and validation. J Chronic Dis. 1987;40:373-383.

19. Weiner JP, Starfield BH, Steinwachs DM, Mumford LM. Development and application of a population-oriented measure of ambulatory care case-mix. Med Care. 1991;29:452-472.

20. Gili M, Roca M, Basu S, McKee M, Stuckler D. The mental health risks of economic crisis in Spain: evidence from primary care centres, 2006 and 2010. Eur J Public Health. 2012;23:103-108.

21. Agudelo-Suárez AA, Ronda E, Vázquez-Navarrete ML, García AM, Martínez JM, Benavides FG. Impact of economic crisis on mental health of migrant workers: what happened with migrants who came to Spain to work? Int J Public Health. 2013;58:627-631.

22. Peiró S, Meneu R. Economic crisis and healthcare system epicrisis. Aten Primaria. 2011;43:115-116.

23. Agencia Española de Medicamentos y Productos Sanitarios [Spanish Agency for Medicines and Health Products]. Utilización de medicamentos antidepresivos en España durante el periodo 2000-2013 [Utilization of antidepressants in Spain during the period 2000-2013]. Available from: http://www.aemps.gob.es/informa/boletin Mensual. Accessed January 2015.
24. Keenan R, O'Hare J. Down in the wards: point prevalence of antidepressant and benzodiazepine use. Ir Med J. 2014;107:92.

25. Piek E, van der Meer K, Nolen WA. Guideline recommendations for long-term treatment of depression with antidepressants in primary care-a critical review. Eur J Gen Pract. 2010;16:106-112.

26. Thase ME. Antidepressant combinations: widely used, but far from empirically validated. Can J Psychiatry. 2011;56:317-323.

27. Souery D, Serretti A, Calati R, et al. Switching antidepressant class does not improve response or remission in treatment-resistant depression. J Clin Psychopharmacol. 2011;31:512-516.

28. Papakostas GI. Managing partial response or non-response: switching, augmentation, and combination strategies for major depressive disorder. $J$ Clin Psychiatry. 2009;70(suppl 6):16-25.

29. Krahn DD, Bartels SJ, Coakley E, et al. PRISM-E: comparison of integrated care and enhanced specialty referral models in depression outcomes. Psychiatr Serv. 2006;57:946-953.

30. Caballero-Martínez F, León-Vázquez F, Payá-Pardo A, Díaz-Holgado A. Use of health care resources and loss of productivity in patients with depressive disorders seen in primary Care: INTERDEP Study. Actas Esp Psiquiatr. 2014;42:281-291.
Neuropsychiatric Disease and Treatment

\section{Publish your work in this journal}

Neuropsychiatric Disease and Treatment is an international, peerreviewed journal of clinical therapeutics and pharmacology focusing on concise rapid reporting of clinical or pre-clinical studies on a range of neuropsychiatric and neurological disorders. This journal is indexed on PubMed Central, the 'PsycINFO' database and CAS,

\section{Dovepress}

and is the official journal of The International Neuropsychiatric Association (INA). The manuscript management system is completely online and includes a very quick and fair peer-review system, which is all easy to use. Visit http://www.dovepress.com/testimonials.php to read real quotes from published authors. 